\title{
Caudal block analgesia for paediatric infra-umbilical surgery: A prospective observational study
}

\section{Gautam B', Karki M²}

${ }^{1}$ Binod Gautam, Associate Professor; ${ }^{2}$ Manan Karki, MD Resident, Department of Anaesthesiology and Intensive Care, Kathmandu Medical College Teaching Hospital, Kathmandu, Nepal.

\begin{abstract}
Background: Caudal block is the most common regional anaesthesia technique used in children. It offers excellent perioperative analgesia in infra-umbilical surgeries. However, large-scale studies on caudal block in our paediatric population are not available.

Objectives: We aimed to evaluate practice pattern, efficacy and safety of caudal block in paediatric infra-umbilical surgery.

Methodology: Children (age less than 14 years) undergoing elective infra-umbilical surgery under general anaesthesia were included in this prospective observational study conducted over two years. Demographic characteristics, type of surgery, anaesthetic techniques and agents used, and details of caudal block were recorded. Perioperative events, complications and duration of analgesia were studied. Eligible children not receiving caudal block served as the control group. Analysis was performed using IBM Statistical Package for the Social Sciences version 20.

Results: Caudal block was employed in 72 out of 183 children who completed the study. It was mostly preferred for children weighing less than 20 kilograms. Ketamine pre-medication was used in 123 children. Majority received Propofol induction and laryngeal mask. Halothane was preferred over Isoflurane for anaesthesia maintenance. Bupivacaine was the exclusively used local anaesthetic agent. Vascular puncture occurred in three children but no serious complication was observed. Need for supplement intraoperative analgesics was significantly lower, and duration of analgesia was significantly longer in caudal group. Intraoperative hypotension, laryngospasm during emergence and postoperative vomiting were the most frequent perioperative events.

Conclusion: Pre-incisional single-shot caudal block is safe, effective and well accepted component of multi-modal perioperative analgesic regimen for younger children undergoing infra-umbilical surgery.
\end{abstract}

Key words: Analgesia; Caudal block; Infra-umbilical surgery; Paediatric; Regional anaesthesia.

DOI: https://doi.org/10.3126/jkmc.v8i3.29713

\section{INTRODUCTION}

Dain management is an integral part of anaesthesia - care in children. Inadequate analgesia not only results in uncooperative and restless children postoperatively, but may also predispose to longterm negative psychological effects. It is preferred to prevent the onset of surgical pain rather than to

\section{Address for correspondence}

\section{Dr. Binod Gautam}

Department of Anaesthesiology and Intensive Care

Kathmandu Medical College Teaching Hospital

Sinamangal, PO Box: 21266, Kathmandu, Nepal.

E-mail: gautambinod@hotmail.com

ORCID: https://orcid.org/0000-0001-5477-6566

ORCID: Manan Karki: https://orcid.org/0000-0003-1706-3895 relieve its existence. Pre-emptive approach and multimodal regimens are advised for this purpose. For the most infants and children, general anaesthesia (GA) is combined with regional anaesthesia techniques (RA) which offers various advantages including reduced analgesic requirements, early extubation, decreased pulmonary complications and early discharge ${ }^{1}$.

Single-shot pre-incisional caudal block (CB) is the most common RA used for perioperative analgesia in paediatric surgeries. As first described by Campbell in 1933, CB is performed by injecting local anaesthetic agent in to the lowest portion of epidural space through the sacral hiatus ${ }^{2}$. It lowers neuro-endocrine responses to surgery and reduces consumption of intraoperative inhaled anaesthetics and opioids 3,4. Infra-umbilical surgeries, the most frequent paediatric procedures in 
our experience, are most amenable to CB analgesia. Usefulness of caudal route has also been extended to abdominal and cardio-thoracic surgeries ${ }^{5,6}$. In our paediatric surgical population, however, there are no studies evaluating clinical practice patterns of CB.

The objectives of this study included evaluation of acceptance, efficacy and safety of pre-incisional $C B$ in infants and children undergoing infra-umbilical surgery under GA. Various aspects of $C B$ including patient selection, technique, type and dose of agents, intraoperative analgesic requirements, duration of analgesia and complications were studied.

\section{METHODOLOGY}

This is a prospective observational study conducted from January 2017 to December 2018 at the setting of operating room, postanaesthesia care unit (PACU) and surgical ward of a teaching hospital. Ethical clearance was obtained from the local Institutional Review Committee. Informed written consent was taken from the parents of eligible children.

Children of age up to 14 years undergoing elective infra-umbilical surgeries including inguinal hernia repair, circumcision, orchidopexy or hypospadias repair comprised the source of eligible participants. Children in whom surgery was planned under sole RA were not considered eligible. Patients who received $C B$ in conjunction with GA were designated as caudal group. Presence of bleeding-clotting disorders, local infections, sepsis, vertebral anomaly, and body weight less than two kilograms comprised the exclusion criteria. Eligible children who did not receive $C B$ due to any reason (exclusion criteria, lack of consent, block failure or based on anaesthesiologist's decision) were similarly followed and they served as the control group for comparison.

Anaesthesia management and treatment options were based on the caring anaesthesiologist's preference and clinical judgments. No changes in patient care due to collection of data was ensured by the authors not getting involved in the decision-making and by recording the study variables from the anaesthesia chart within one hour after the child reached the PACU. Any unfilled pertinent information was recorded by consulting the involved anaesthesiologist/trainee resident. All postoperative managements were based on principal surgeon's discretion and study variables were recorded from the nursing chart at six hour interval.

Demographic characteristics included the patient's age, gender, weight and American Society of
Anesthesiologists' (ASA) physical status. Surgical profile included diagnosis, type and duration of surgery (defined as surgical incision to skin closure).

Details regarding premedication (route and agent), anaesthesia induction and maintenance (route and agent), airway management, analgesics, type of local or RA employed and any other medication administered to prevent or treat adverse events was recorded. Administration of analgesic (Opioids, Ketamine, or any other) after the initiation of surgical incision was recorded as intraoperative supplement analgesic.

Recorded variables regarding caudal block included; technique used for identification of caudal space (landmark or ultrasound guided), use of "swoosh test", use of "test dosing", local anaesthetic type, dose and volume(per kg body weight), adjuvant type and dose (per kg body weight), and complications. Complication from CB was defined as any of the following: block failure (unable to place, difficult to inject, subcutaneous injection), vascular puncture (defined by the presence of blood with aspiration), dural puncture (defined by the presence of cerebrospinal fluid with aspiration), seizure, respiratory arrest, cardiac arrest, sacral pain or neurologic symptoms. If a complication was recorded, the presence of temporary and/or permanent outcome was followed until resolved.

Patients were followed for events (nausea, vomiting, headache, urinary retention and any other), and use of medication till their discharge from hospital. Duration of analgesia was recorded as the time from $C B$ to the time of first postoperative analgesic administration. Postoperatively, type of analgesics used and duration of hospital stay were also recorded.

Statistical package for social science evaluation version 20 (IBM-SPSS20 Inc; Chicago, IL, USA) was used for analysis. Quantitative variables are expressed as mean (standard deviation). Qualitative variables are presented as number (percentage) and evaluated using Fisher exact test. Relative risk (95\% confidence interval) was calculated for binary outcomes. Use of CB in relation to patient's age, weight and surgery type was evaluated. Need for intraoperative supplement analgesics, duration of analgesia, and events/complications were compared between the caudal group and the control group. Subgroupanalysis for duration of postoperativeanalgesia with respect to use of Ketamine pre-medication, caudal adjuvant and intraoperative Paracetamol were also performed. Two-tailed $P$ values less than 0.05 were used in order to reject null hypotheses. 


\section{RESULTS}

During the study period 183 children were confirmed eligible for the study. Seventy two children received CB (Figure 1). Demographic and surgical characteristics of participants who were all considered as ASA I physical status are presented in table 1. Monitoring during surgery included standard ASA monitors.

One hundred and eleven children received some form of pre-incisional loco-regional anaesthesia other than CB after being induced with GA. Selection of RA in the participants according to their age, body weight and type of surgery are shown in figures 2,3 , and 4 respectively.

All CB were performed in left lateral decubitus position using landmark technique. "Swoosh test" was employed for identification of caudal epidural space in 15 patients. Formal use of "test dosing" was employed in five of the patients. Particulars of CB are shown in Table 2. Dexmedetomidine at a dose of 0.75 to two micrograms/ $\mathrm{kg}$ was the only used caudal adjuvant. No serious complication including seizure, cardiac arrest, respiratory arrest or neurologic symptoms was observed.

Distribution of children according to the anaesthetic management is shown in Table 3. Intraoperative events and need for supplement analgesics during surgery are represented in Table 4. Laryngospasm and desaturation were observed in 10 children immediately after removal of LMA.

Duration of analgesia and postoperative course are presented in Table 5. Duration of analgesia was significantly prolonged in caudal group as compared to control group. Subgroup analysis shows that duration of analgesiawassignificantlylongerinchildren whoreceived caudal adjuvant (540 \pm 76.48 vs. $254.25 \pm 93.31$ minutes) but there was no significant difference with respect to use of Ketamine premedication (221.34 \pm 114.93 vs. $211.75 \pm 135.35$ minutes) and intraoperative Paracetamol ( $231.94 \pm 134.99$ vs. $211.65 \pm 114.86$ minutes).

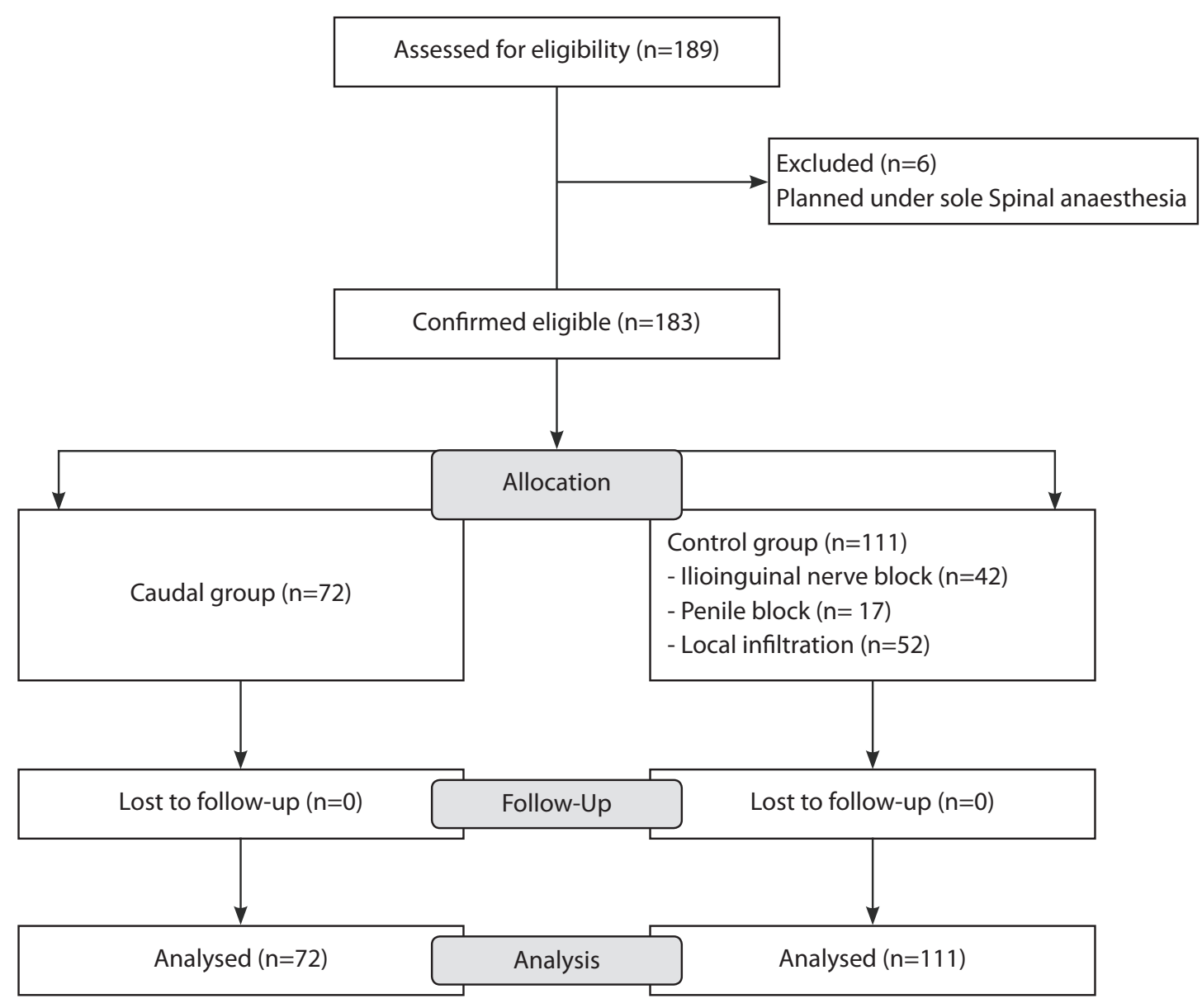

Figure 1: Flow diagram of the study (values in number) 


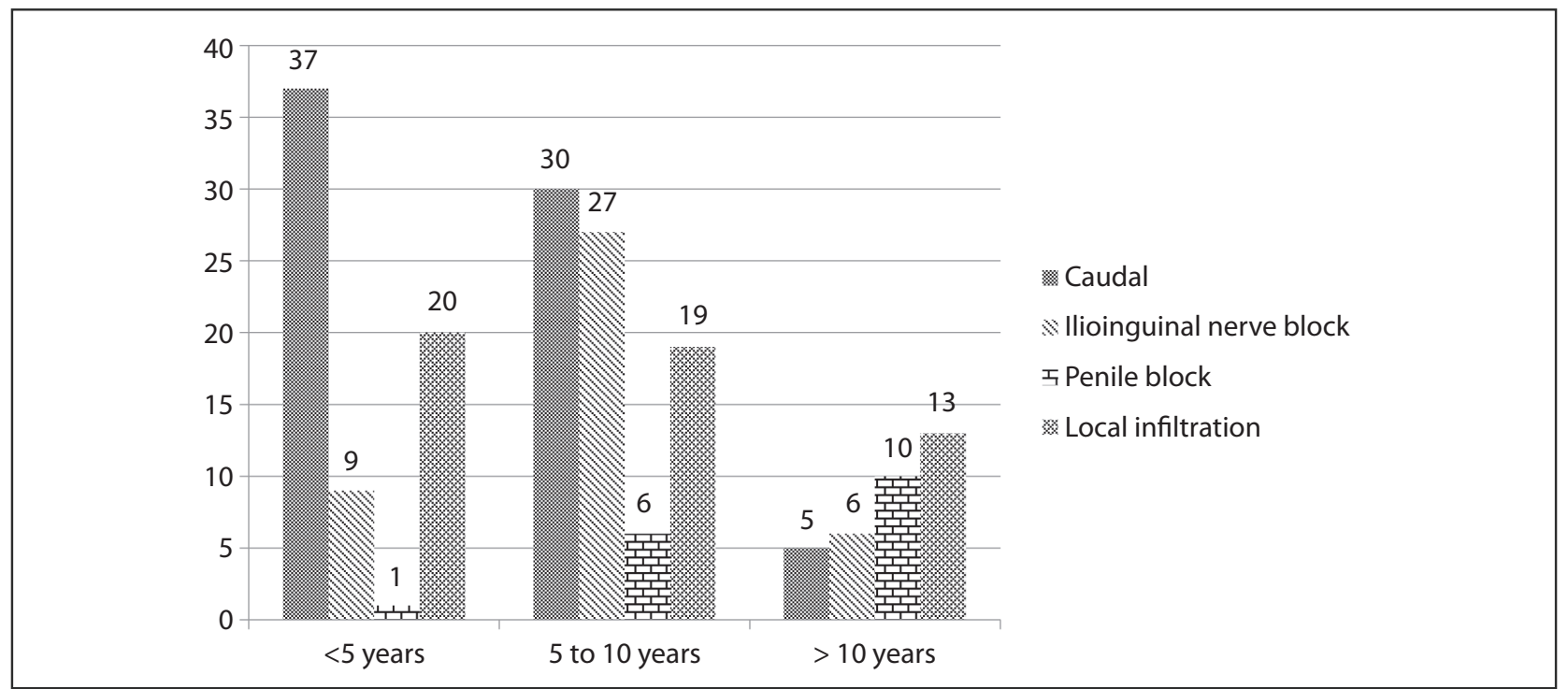

Figure 2: Distribution of regional anaesthesia according to age group (values are number of patients).

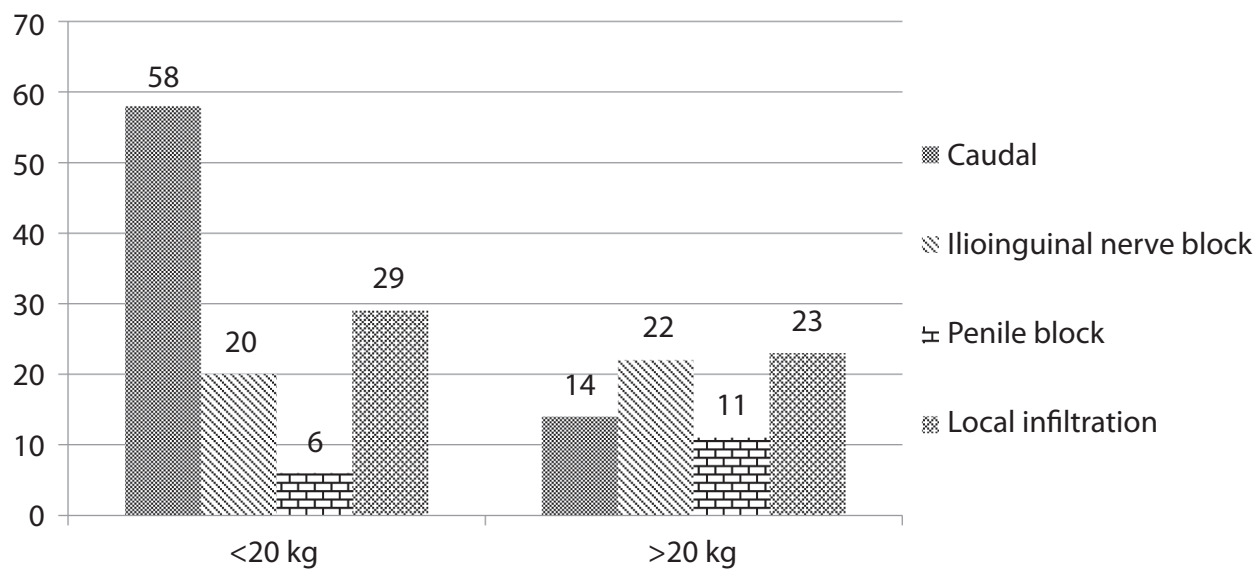

Figure 3: Distribution of regional anaesthesia according to weight (values are number of patients).

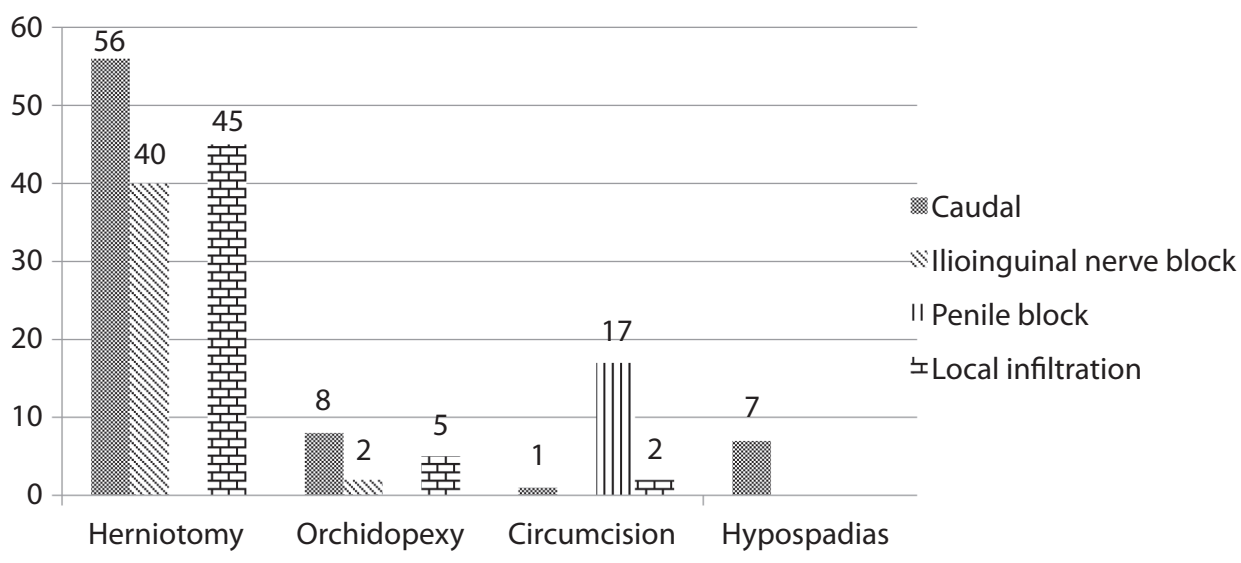

Figure 4: Distribution of regional anaesthesia according to type of surgery (values are number of patients). 
Table 1: Demographic and surgical characteristics

\begin{tabular}{|c|c|c|c|}
\hline & Caudal group $(n=72)$ & Control group $(n=111)$ & p-value \\
\hline Age (years) ${ }^{*}$ & $5.4( \pm 3.05)$ & $7.02( \pm 3.77)$ & 0.03 \\
\hline \multicolumn{4}{|l|}{ Gender ( $n)$} \\
\hline Male : Female & $52: 20$ & $93: 18$ & 0.06 \\
\hline Body weight (kilograms) ${ }^{*}$ & $17.06( \pm 5.23)$ & $22.27( \pm 8.23)$ & 0.00 \\
\hline \multicolumn{4}{|l|}{ Surgery type, $\mathrm{n}$ (percentage) } \\
\hline Inguinal hernia repair & $56(77.7)$ & $85(76.5)$ & \\
\hline Orchidopexy & $8(11.1)$ & $7(6.3)$ & 0.843 \\
\hline Circumcision & $1(1.39)$ & $19(17.11)$ & \\
\hline Hypospadias repair & $7(9.7)$ & $0(0)$ & \\
\hline Duration of surgery (minutes) ${ }^{*}$ & $81.88( \pm 38.27)$ & $62.16( \pm 19.67)$ & 0.000 \\
\hline Amount of intraoperative fluid infused (ml) ${ }^{*}$ & $187.08( \pm 106.3)$ & $189.73( \pm 91.8)$ & 0.858 \\
\hline
\end{tabular}

*Values are mean ( \pm standard deviation) and $\mathrm{p}$ value calculated using Student's t-test

Table 2: Agents used and complications of caudal block

\begin{tabular}{lc}
\hline Parameter & Value \\
Local anaesthetic (Bupivacaine) & 0.25 \\
$\quad$ Concentration (percentage) & 1.5 to 2 \\
$\quad$ Dose range (mg/kg body weight) & 0.8 to 1 \\
$\quad$ Volume range (ml/kg body weight) & $5(6.9)$ \\
Caudal adjuvant, $\mathrm{n}(\%)$ & $3(4.1)$ \\
Dexmedetomidine & \\
\hline$\quad$ Vomplications, $\mathrm{n}(\%)$ & \\
\hline
\end{tabular}

Table 3: Techniques of anaesthesia

\begin{tabular}{|c|c|c|c|}
\hline & Caudal group $(n=72)$ & Control group $(n=111)$ & p-value \\
\hline Pre-medication & $56(77.7)$ & $87(78.3)$ & \\
\hline \multicolumn{4}{|l|}{ Route } \\
\hline IV & 37 & 70 & \multirow{2}{*}{0.324} \\
\hline $\mathrm{IM}$ & 19 & 17 & \\
\hline \multicolumn{4}{|l|}{ Agent } \\
\hline Ketamine+Glycopyrrolate & 52 & 71 & \multirow{2}{*}{0.543} \\
\hline Midazolam & 4 & 16 & \\
\hline \multicolumn{4}{|l|}{ Opioid analgesic (pre-incision) } \\
\hline Fentanyl & $53(73.6)$ & $82(73.8)$ & \multirow{2}{*}{0.969} \\
\hline Dose (microgram/kg) & 0.5 to 1 & 0.5 to 1 & \\
\hline \multicolumn{4}{|l|}{ Induction } \\
\hline Inhalational (Halothane) & $21(29.1)$ & $25(22.5)$ & \multirow{2}{*}{0.314} \\
\hline Intravenous (Propofol) & $51(70.8)$ & $86(77.4)$ & \\
\hline \multicolumn{4}{|l|}{ Airway management } \\
\hline LMA & $72(100)$ & $108(97.3)$ & \multirow{2}{*}{0.161} \\
\hline Mask & $0(0)$ & $3(2.7)$ & \\
\hline \multicolumn{4}{|l|}{ Anaesthesia maintenance } \\
\hline Halothane & $67(93.05)$ & $92(82.8)$ & \multirow[b]{2}{*}{0.047} \\
\hline Isoflurane & $5(6.94)$ & $19(17.11)$ & \\
\hline Paracetamol & $36(50)$ & $86(77.4)$ & \multirow{4}{*}{$<0.001$} \\
\hline \multicolumn{3}{|l|}{ Route } & \\
\hline Per rectal & 21 & 44 & \\
\hline Intravenous & 15 & 42 & \\
\hline
\end{tabular}

Values are number (percentage); LMA: laryngeal mask airway; IV: intravenous; IM: intramuscular 
Table 4: Intraoperative events and medications

\begin{tabular}{|c|c|c|c|c|}
\hline & $\begin{array}{l}\text { Caudal group } \\
\qquad(n=72)\end{array}$ & $\begin{array}{l}\text { Control group } \\
\qquad(n=111)\end{array}$ & $\begin{array}{l}\text { Relative risk } \\
\qquad(95 \% \mathrm{CI})\end{array}$ & p-value \\
\hline $\begin{array}{l}\text { Prophylactic } \\
\text { Anticholinergic } \\
\text { (Glycopyrrolate) }\end{array}$ & $19(26.3)$ & $19(17.11)$ & $1.542(0.878-2.706)$ & 0.140 \\
\hline $\begin{array}{l}\text { Anti-emetic prophylaxis } \\
\text { (Dexamethasone) }\end{array}$ & $2(2.77)$ & $5(4.5)$ & $0.613(0.123-3.094)$ & 0.706 \\
\hline Supplement analgesics & $15(20.83)$ & $36(32.43)$ & $0.788(0.652-0.951)$ & 0.008 \\
\hline Fentanyl & 3 & 10 & & \\
\hline Ketamine & 4 & 12 & & \\
\hline Ketorolac & 8 & 14 & & \\
\hline Vasopressor for Hypotension & $6(8.3)$ & $7(6.3)$ & $1.321(0.463-3.774)$ & 0.769 \\
\hline Atropine for Bradycardia & $1(1.3)$ & $2(1.8)$ & $0.771(0.071-8.346)$ & 1 \\
\hline Laryngospasm & $3(4.16)$ & $7(6.3)$ & $0.661(0.177-2.472)$ & 0.742 \\
\hline
\end{tabular}

$\mathrm{Cl}$ : confidence interval; values are number (percentage); $\mathrm{p}$ value calculated with Fisher exact test

Table 5: Duration of analgesia and postoperative events

\begin{tabular}{|c|c|c|c|c|}
\hline & $\begin{array}{l}\text { Caudal group } \\
\qquad(n=72)\end{array}$ & $\begin{array}{l}\text { Control group } \\
(n=111)\end{array}$ & $\begin{array}{l}\text { Relative risk } \\
\qquad(95 \% \mathrm{CI})\end{array}$ & p-value \\
\hline Duration of analgesia (min)* & $274.09( \pm 117.36)$ & $181.93( \pm 110.67)$ & & 0.000 \\
\hline \multicolumn{5}{|l|}{ Post-operative analgesics, n (\%) } \\
\hline Oral Paracetamol & $3(4.1)$ & $3(2.7)$ & & \multirow{3}{*}{0.835} \\
\hline Oral Paracetamol+lbuprofen & 59 (81.9) & $93(83.7)$ & & \\
\hline Ketorolac & $10(13.8)$ & $15(13.5)$ & & \\
\hline Need for anti-emetics, n (\%) & $8(11.1)$ & $6(5.4)$ & $2.056(0.744-5.678)$ & 0.158 \\
\hline Urinary retention, $\mathrm{n}(\%)$ & $4(5.55)$ & $5(4.5)$ & $1.233(0.343-4.440)$ & 0.750 \\
\hline Duration of hospital stay (days)* & $2.23( \pm 1.35)$ & $1.99( \pm 0.65)$ & & 0.104 \\
\hline
\end{tabular}

$\mathrm{Cl}$ : confidence interval; *values are mean ( \pm standard deviation) and p value calculated using Student's t-test

\section{DISCUSSION}

The most important finding of our study was that caudal block was the most preferred RA for perioperative analgesia in infants and younger children who weighed less than 20 kilograms and for anticipated complex and prolonged infra-umbilical surgery. In addition, a lower need for intraoperative supplement analgesics and a prolonged pain-free period was observed in children receiving caudal block. Although procedure had to be abandoned due to vascular puncture in three children, no case of serious complication was observed. Taken together, the findings suggest that $C B$ is well accepted, effective and safe RA performed in paediatric surgical population.

$C B$ is one of the most common RA used in children, both to supplement $G A$ and provide postoperative analgesia ${ }^{1,7}$. Rate of use of $C B$ among eligible children in our study represents the anaesthesiologist's clinical decision. The choice may actually depend upon various factors including patient's demographic profile, type of surgery and presence of conditions that complicate or contraindicate for the performance of CB. Time factor and a need to teach trainee residents may also be implicated. CB was chosen invariably for the most prolonged and complex surgery such as hypospadias repair (Figure 4). Tendencies for avoiding caudal block in children above 10 years and a body weight more than 20 kilograms were observed (Figures 2 and 3). It shows a preference towards easier and less time-consuming alternatives in these group of children ${ }^{8,9}$. Also, for boys old enough to walk, penile block was preferred for circumcision most probably to avoid possible temporary leg weakness associated with CB.

Wide ranges of multi-modal agents and techniques have been employed during surgery for improving pain relief and which determines the duration of postoperative analgesia. Use of intraoperative Paracetamol was significantly higher in the control group implying that CB is comparatively more trusted for its efficacy among the feasible regional analgesic techniques (Table 3). 
A significantly longer time before the first analgesic administration in children from caudal group, despite receiving less frequent intraoperative Paracetamol in our study was thus most probably due to the technique itself. Also, subgroup analyses showed that duration of analgesia was significantly prolonged by only the use of caudal adjuvant but not the Ketamine premedication or intraoperative Paracetamol. Similarly, doses of intraoperative analgesics and surgical complexity could be contributory. The same factors could prove crucial in determining the need for intraoperative supplement analgesics which was significantly higher in the control group as compared to the caudal group in our study, even though the time to surgical incision from the time of caudal injection varied.

The duration of analgesia provided by CB can be extended by adjuvant drugs, which are administered into the caudal space, together with local anaesthetics. Among many drugs tried, Morphine, Ketamine, and Clonidine seem to be clinically useful ${ }^{1,7}$. Dexmedetomidine was the only used caudal adjuvant in our study (Table 2). Its application is on the rise as it became available in our set up. Dexmedetomidine has been shown to be effective and safe in $\mathrm{CB}^{10,11}$. At a dose range of 0.75 to two mcg/kg used in the study it significantly prolonged the duration of analgesia.

Bupivacaine was the sole local anaesthetic used and we did not detect a large variation in its dose (Table 2). Bupivacaine is readily available, has a long duration of action and its side effects are very well known 1,12,13. Hemodynamic effects of $C B$ comprise vasodilation secondary to sympathetic nervous system blockade. However, blood pressures and heart rates are minimally affected $^{14}$. Negligible incidence of intraoperative bradycardia and hypotension in our patients also emphasizes it. Frequent use of Ketamine premedication and prophylactic anti-cholinergics (Glycopyrrolate) in both the groups could also have contributed (Tables 3 and 4).

Laryngeal mask was inserted in all of our participants except for three (Table 3). It provides a safe and effective form of airway management for infants and children both for spontaneous and controlled ventilation. Laryngeal mask has become the device of choice in routine paediatric anaesthesia practice ${ }^{15,16}$. It avoids procedure-related discomfort and patient's positionrelated difficulties. However, laryngospasm was observed during LMA removal in 10 children (Table 4). It responded well with the application of continuous positive airway pressure except in two who received low dose of Succinylcholine. Laryngospasm is a potentially severe complication of anaesthesia in younger children with a multifactorial etiology. Its overall incidence is shown to be at 7.9/1000 anaesthetics or $8.7 / 1000$ patients ${ }^{17}$. The most important risk factor is pre-existent respiratory dysfunction followed by light anaesthesia, pain, and irritant factors such as blood, mucus and airway manipulations. Also, variations in timing and position of child during LMA removal could be responsible ${ }^{18}$.

Choice of pre-medication and anaesthesia induction mostly depends upon age, psychological makeup and responses of the child together with the resources available. Ketamine combined with Glycopyrrolate was the most common pre-medication strategy observed in the study (Table 3). Easy availability, wide margin of safety, analgesic property and versatility in routes of administering Ketamine are well known ${ }^{19,20}$. Although painful upon injection, intramuscular Ketamine has long been used in our set up for its predictable effects in facilitating parent-child separation.

In our study intravenous Propofol was the most common inducing agent. It allows faster onset of action, shorter duration of action and a lower incidence of postoperative nausea/vomiting ${ }^{21,22}$. Propofol has become the agent of choice for induction in infants and children. However, in children who do not tolerate intravenous cannulation, inhalational induction continues to be a better option. Sevoflurane is replacing Halothane as the drug for inhalational induction? ${ }^{7}$. But, being the only suitable agent available, Halothane was exclusively used for that purpose in our children. It results in smooth trouble free induction and has proven its safety in experienced hands. And, it is associated with lower incidence of emergence agitation in children when compared to Sevoflurane ${ }^{23}$. Halothane was also favored over Isoflurane for anaesthesia maintenance in our study (Table 3). Due to less incidence of laryngospasm and coughing during induction and emergence, Halothane may still be preferred in children for short procedures ${ }^{24}$.

Postoperatively, no children received opioids for pain relief. The residual effects of RA and use of regular oral Paracetamol and lbuprofen combination could have been responsible ${ }^{25}$. The most common postoperative event of importance was the need for anti-emetics to treat vomiting in our study. Still, the incidence was comparable with the previous finding ${ }^{26}$. Postoperative nausea and vomiting in children originates from multiple factors. Groin surgery and penile surgery may have a modest increased incidence ${ }^{26}$. Use of inhalational agents for anaesthesia maintenance may also contribute ${ }^{27,28}$. 
Urinary retention occurring in our participants was managed with in-out Foley's catheterization that did not affect the overall outcomes.

Success rate of caudal block was high in our study, even though there was variation in the experience of the performer. Three patients in our study had vascular puncture and blood aspirations; and, the procedure was abandoned but subsequent harm was not observed. Ultrasound guidance, which was not used in our study, can improve the identification of sacral hiatus thereby facilitating proper needle advancement. But, since these blocks are relatively easy to perform in children, ultrasound may not be significantly advantageous over landmark-based techniques.

Low incidence of complications related to $C B$ in our study coincides with previous studies ${ }^{29-31}$. Inadvertent intravascular injection occurs at a rate of 1:10000 up to $0.4 \%$ while epidural hematoma occurs in 1:80000 pediatric caudal blocks ${ }^{30,31}$. This demonstrates the importance of performing epinephrine-containing "test dosing". However, very infrequent practice of "swoosh test" and a formal "test dosing" observed in our study calls for their recommendation, which might further improve success rate, efficacy and safety.

Our study represents the practice patterns of anaesthesia in a single institution. It included a wide age-range of children undergoing different types of surgery. The findings must thus be interpreted within the context of its limitations. Anaesthetic management was not protocol-based and defining the perioperative events and use of medication were the reflection of individual anaesthesiologist's usual clinical practice. Similarly, objective assessment of postoperative pain was lacking and time to administer first analgesic was subject to the caring nurses' judgment.

Even though caudal block may require extra time and expense, a child with a prolonged pain-free state in the postoperative period helps to preserve the anaesthesiologist's enthusiasm in employing it. The findings could also be generalized to children appearing for lower limb/orthopedic, urologic and appendix surgery. Given the safety of caudal blocks as observed in our study, the performance of randomized clinical trial is justified not only to establish its surgery-specific efficacy but also to detect optimal local anaesthetic dose regimens and effects of adjuvants in our paediatric surgical population.

\section{CONCLUSION}

Caudal block is a preferred regional anaesthetic technique with a high success rate in paediatric surgical population, especially in children younger than five years of age, weighing 20 kilograms or less and those undergoing inguino-scrotal surgery except for circumcision. In conjunction with general anaesthesia, it can be easily performed with landmark-based technique in infants and children. For infra-umbilical surgeries, caudal block may reduce need for intraoperative analgesics, prolongs pain-free postoperative period and minimizes the need for opioids, with a very low incidence of complications or side effects.

children: a simple calculation of the volume of local anaesthetic. Acta Anaesthesiol Scand. 1984 Feb;28(1):57-60. [PubMed][DOI]

6. Nguyen KN, Byrd HS, Tan JM. Caudal analgesia and cardiothoracic surgery: a look at postoperative pain scores in a pediatric population. Paediatr Anaesth. 2016 Nov;26(11):1060-3. [PubMed][DOI]

7. Russell SCS, Doyle E. Recent advances: Paediatric anaesthesia. BMJ. 1997;314:201-3.[Full Text]

8. Suresh S, Schaldenbrand K, Wallis B, De Oliveira Jr GS. Regional anaesthesia to improve pain outcomes in pediatric surgical patients: a qualitative systematic review of randomized controlled trials. $\mathrm{Br} J$ Anaesth. 2014;113(3):375-90.[Full Text]

9. Baird R, Guilbault MP, Tessier R, Ansermino JM. A systematic review and meta-analysis of caudal blockade versus alternative analgesic strategies for pediatric inguinal hernia repair. J Pediatr Surg. 2013 May;48(5):1077-85. [PubMed][DOI] 
10. Saadawy I, Boker A, Elshahwy MA, Almazrooa A, Melibary S, Abdellatif AA, et al. Effect of dexmedetomidine on the characteristics of bupivacaine in a caudal block in pediatrics. Acta Anaesthesiol Scand. 2009; 53(2): 251-6. [FullText]

11. El-Hennawy AM, Abd-Elwahab AM, Abd-Elmaksoud AM, El-Ozairy HS, Boulis SR. Addition of clonidine or dexmedetomidine to bupivacaine prolongs caudal analgesia in children. Br J Anaesth. 2009 Aug;103(2): 268-74. [PubMed][Full Text]

12. Verghese ST, Hannallah RS, Ric LJ, Belman AB, Patel KM. Caudal anesthesia in children: Effect of volume versus concentration of bupivacaine on blocking spermatic cord traction response during orchidopexy. Anesth Analg. 2002;95(5):1219-23. [FullText]

13. Patel D. Epidural analgesia for children. Br J Anaesth. 2006;6(2):63-6. [FullText]

14. Larousse E, Asehnoune K, Dartayet B, Albaladejo P, Dubousset AM, Gauthier F, et al. The hemodynamic effects of pediatric caudal anesthesia assessed by esophageal Doppler. Anesth Analg. 2002 May;94(5):1165-8. [PubMed][FullText]

15. Lopez-Gil M, Brimacombe J, Alvarez M. Safety and efficacy of the laryngeal mask airway. A prospective survey of 1400 children. Anaesthesia. 1996 Oct;51(10):969-72. [PubMed][FullText]

16. Bradely $A E$, White $M C$, Engelhardt $T$ Bayley $G$, Beringer RM. Current UK practice of pediatric supraglottic airway devices - survey of members of the Association of Paediatric Anaesthetists of Great Britain and Ireland. Paediatr Anaesth. 2013 Nov;23(11):1006-9. [PubMed][FullText]

17. Olsson GL, Hallen B. Laryngospasm during anaesthesia. A computer-aided incidence study in 136,929 patients. Acta Anaesthesiol Scand. 1984 Oct;28(5):567-75. [PubMed][DOI]

18. Thomas-Kattappurathu G, Kasisomayajula A, Short J. Best position and depth of anaesthesia for laryngeal mask airway removal in children: A randomized controlled trial. Eur J Anaesthesiol. 2015;32(9):62430. [FullText]

19. Roelofse JA. The evolution of ketamine applications in children. Pediatr Anesth. 2010;20:240-5. [Full Text]

20. Green SM, Rothrock SG, Lynch EL, Ho M, Harris $T$, Hestadlen $R$, et al. Intramuscular ketamine for pediatric sedation in the emergency department: safety profile in 1,022 cases. Ann Emerg Med. 1998;31:688-97.[DOI]

21. Song D, Hamza M, White PF, Klein K, Recart A, Khodaparast $\mathrm{O}$. The pharmacodynamics effects of a lower-lipid emulsion of propofol: A comparison with the standard propofol emulsion. Anesth Analg. 2004 Mar;98(3):687-91. [PubMed] [FullText]

22. Vardi A, Salem Y, Padeh S, Paret G, Barzilay Z. Is propofol safe for procedural sedation in children? A prospective evaluation of propofol versus ketamine in pediatric critical care. Crit Care Med. 2002 Jun;30(6):1231-6. [PubMed]

23. Kuratani N, Oi Y. Greater incidence of emergence agitation in children after sevoflurane anesthesia as compared to halothane: A meta-analysis of randomized controlled trials. Anesthesiology. 2008;109(2):225-32. [FullText]

24. Fisher DM, Robinson S, Brett CM, Perin G, Gregory GA. Comparison of enflurane, halothane, and isoflurane for diagnostic and therapeutic procedures in children with malignancies. Anesthesiology. 1985 Dec;63(6):647-50. [PubMed] [FullText]

25. Ong CK, Seymour RA, Lirk P, Merry AF. Combining paracetamol (acetaminophen) with nonsteroidal anti-inflammatory drugs: a qualitative systematic review of analgesic efficacy for acute postoperative pain. Anesth Analg. 2010 Apr;110(4):1170-9. [PubMed][FullText]

26. Byers GF, Doyle E, Best CJ, Morton NS. Postoperative nausea and vomiting in paediatric surgical inpatients. Paediatr Anaesth. 1995;5(4):253-6.[DOI]

27. Apfel CC, Kranke P, Katz MH, Goepfert C, Papenfuss $\mathrm{T}$, Rauch $\mathrm{S}$, et al. Volatile anaesthetics may be the main cause of early but not delayed postoperative vomiting; a randomized controlled trial of factorial design. Br J Anaesth. 2002 May;85(5):659-68. [PubMed][FullText]

28. Sneyd JR, Carr A, Byrom WD, Bilski AJ. A meta-analysis of nausea and vomiting following maintenance of anaesthesia with propofol or inhalational agents. Eur J Anaesthesiol. 1998 Jul;15(4):433-45.[PubMed] [FullText]

29. Suresh S, Long J, Birmingham PK, De Oliveira GS. Are caudal blocks for pain control safe in children? An analysis of 18,650 caudal blocks from the pediatric regional anesthesia network (PRAN) database. Anesth Analg. 2015;20(1):151-6. [PubMed][FullText]

30. Dalens B, Hasnaoui A. Caudal anesthesia in pediatric surgery: Success rate and adverse effects in 750 consecutive patients. Anesth Analg. 1989 Feb;68(2):83-9. [PubMed] [FullText]

31. Giaufre E, Dalens B, Gombert A. Epidemiology and morbidity of regional anesthesia in children: A oneyear prospective survey of the French language society of pediatric anesthesiologists. Anesth Analg. 1996 Nov;83(5):904-12. [PubMed][FullText] 